\title{
Simulation and optimization integrated gasification combined cycle by used aspen hysys and aspen plus
}

\author{
Mohsen Darabi ${ }^{1 *}$, Mohammad Mohammadiun ${ }^{2}$, Hamid Mohammadiun ${ }^{2}$, \\ Saeed Mortazavi ${ }^{3}$, Mostafa Montazeri ${ }^{4}$ \\ ${ }^{1}$ Young Researchers and Elite Club, shahrood Branch, Islamic Azad University, shahrood, Iran \\ ${ }^{2}$ Assistant Professor, Department of Mechanical Engineering, Shahrood Branch, Islamic Azad University, Shahrood, Iran \\ ${ }^{3}$ Assistant Professor, Department of chemical Engineering, Shahrood Branch, Islamic Azad University, Shahrood, \\ ${ }^{4}$ Department of Chemical Engineering, shahrood Branch, Islamic Azad University, Shahrood, Iran \\ *Corresponding author E-mail: mohsendarabi313@yahoo.com
}

Copyright $(9) 2015$ Mohsen Darabi et al. This is an open access article distributed under the Creative Commons Attribution License, which permits unrestricted use, distribution, and reproduction in any medium, provided the original work is properly cited.

\begin{abstract}
Electricity is an indispensable amenity in present society. Among all those energy resources, coal is readily available all over the world and has risen only moderately in price compared with other fuel sources. As a result, coal-fired power plant remains to be a fundamental element of the world's energy supply. IGCC, abbreviation of Integrated Gasification Combined Cycle, is one of the primary designs for the power-generation market from coal-gasification. This work presents a in the proposed process, diluted hydrogen is combusted in a gas turbine. Heat integration is central to the design. Thus far, the SGR process and the HGD unit are not commercially available. To establish a benchmark. Some thermodynamic inefficiencies were found to shift from the gas turbine to the steam cycle and redox system, while the net efficiency remained almost the same. A process simulation was undertaken, using Aspen Plus and the engineering equation solver (EES).The The model has been developed using Aspen Hysys ${ }^{\circledR}$ and Aspen Plus ${ }^{\circledR}$. Parts of it have been developed in Matlab, which is mainly used for artificial neural network (ANN) training and parameters estimation. Predicted results of clean gas composition and generated power present a good agreement with industrial data. This study is aimed at obtaining a support tool for optimal solutions assessment of different gasification plant configurations, under different input data sets.
\end{abstract}

Keywords: Conceptual Modeling; Process Simulation; IGCC Power Plant; Gas Purification Units; Clean Power Production.

\section{Introduction}

Integration of gasification and a combined cycle implies clear advantages as regards to environmental and economic considerations: gasification process contributes to feedstock and product flexibility, and the use of a combined cycle (CC) achieves higher efficiency compared to conventional thermal power plants (around 40-50\%) [1].

The aim of this work is to build a decision support platform in order to obtain a wholly integrated and optimized process operation, including modeling and simulation of the gasifier reactor, cleaning and conditioning stages of produced gases and power generation.

\section{IGCC power plant model development}

The model is implemented using two main chemical flow sheeting environments: Aspen Hysys ${ }^{\circledR}$ and Aspen Plus ${ }^{\circledR}$, which are flexible tools for process simulation by providing thermodynamic models for the estimation of chemical properties and unit operation models for many processes.

Aspen Hysys ${ }^{\circledR}$ has been chosen as the platform for the overall process simulation because of its capability of accepting custom models as extensions. These models could be complex chemical reactions (COS hydrolysis) or complicated unit 
operation (pyrolysis). It also allows creating new chemical components not included in its database, such as nonstoichiometric solids for raw material and char definition.

Alternatively, Aspen Plus ${ }^{\circledR}$ is used for calculations involving water systems and electrolytes. These ionic models are required to solve the phase equilibrium problem for unit operation systems such as venturi scrubbers, sour water strippers or MDEA absorbers. The aforementioned models have been integrated in Aspen Hysys® by means of artificial neural network (ANN) extensions. Data required to train each of the ANN's comes from the sensitivity analysis performed with Aspen Plus ${ }^{\circledR}$ while the neural network training is carried out using the ANN package provided with Matlab 6.5. Matlab is also used for gasifier model parameters estimation.

\section{Assumptions}

Several assumptions throughout this work are made regarding the physical behavior of the industrial plant and others related to the representation of such behavior in the simulation software. In the first case, real plant operating conditions have been adapted to the simulation environment and in the latter case they refer to assumptions adopted within the same software.

Data from ELCOGAS IGCC power plant located in Puertollano (Madrid, Spain) are used to define the flowsheet sequence and for testing and model validation purposes.

According to industrial data, fuel raw material is a mixture of coal and petcoke. Ashes are a mixture of oxides primarily $\mathrm{SiO} 2$ and $\mathrm{Al} 2 \mathrm{O} 3$ with traces of several other metals. Gasifier temperature and pressure operating conditions are shown in Table 1. Percentage of ashes that leave the gasifier reactor as slag and pollutants that pass to chimney emissions together with fly ash, are predicted using experimental correlations [2].

Suspended solids are separated from the synthesis gas (syngas). Thus, no solids are assumed to be present in all downstream units, simplifying the model since only two fluid phases, liquid and vapor, are considered.

Feedstock particles diameter is considered to be uniform and equal to $5.5 \mathrm{~mm}$.

Three Rankine cycles are set, one for each available pressure at the plant site.

The assumptions adopted within the software are:

All solid species considered, raw materials, ashes and char, are treated as Hypo-Components in Aspen Hysys ${ }^{\circledR}$. Raw materials and char are defined using their ultimate analysis and heat of formation.

Thermodynamic properties for phase separation are calculated using Peng-Robinson equation of state.

Conceptual models of every unit considered.

\section{IGCC processes description}

Fig. 1 and Fig. 2 represent two snapshots of the process flow sheet in Aspen Hysys ${ }^{\circledR}$.

An air separation unit (ASU) is used to obtain oxygen at a higher purity (85\%) from air at high pressure. Input streams to this flow sheet section (Fig. 1) are: coal and pet coke mixture, air and demineralized water. Air is mainly used for combustion in a Brayton cycle and to obtain the required flow of oxygen for raw material gasification. Residual nitrogen is used in the CC to reduce NOx emissions. Output streams of this section are: electric power generated from steam and gas turbines and flue gas which is sent out through a chimney. Fuel raw material enters the gasifier unit where it is gasified and converted into syngas; this outlet gas is cooled down before entering the purification units. Heat is recovered by producing steam which is used in the $\mathrm{CC}$ turbines. Clean gas coming from the purification system goes into the CC where it is burned in a Brayton cycle. Steam is produced in a HRSG taking advantage of the high temperature arising from gas combustion before going through the chimney.

Fig. 3 shows the flow sheet which contains all the models that mimic the plant gas purification stages. Water and $\mathrm{pH}$ controlling streams (sodium hydroxide and sulfuric acid solutions) are inlet streams for the venturi and sour water stripper units, respectively. Other inlet streams are oxygen and air to the Claus plant. Water from the sour water stripper, liquid sulfur produced in the Claus plant and fly ashes are outlet streams. In the venturi scrubber, the gas is put into contact with water that absorbs and removes pollutant species (acid and basic species). This water is cleaned downstream in the sour water stripper. Syngas is further purified after its passage through the COS hydrolysis reactor. This unit aims at converting all COS into $\mathrm{H} 2 \mathrm{~S}$, which is next removed in the MDEA absorber, maximizing sulfur retention. Polluted streams from sour water stripper, COS hydrolysis reactor and MDEA absorber are sent to the Claus plant, where sulfur is recovered in a liquid form. A recycle gas stream from the Claus plant goes to the COS hydrolysis reactor to further increase COS conversion. Finally, the obtained clean gas, after the MDEA absorber, is sent into the $\mathrm{CC}$. 


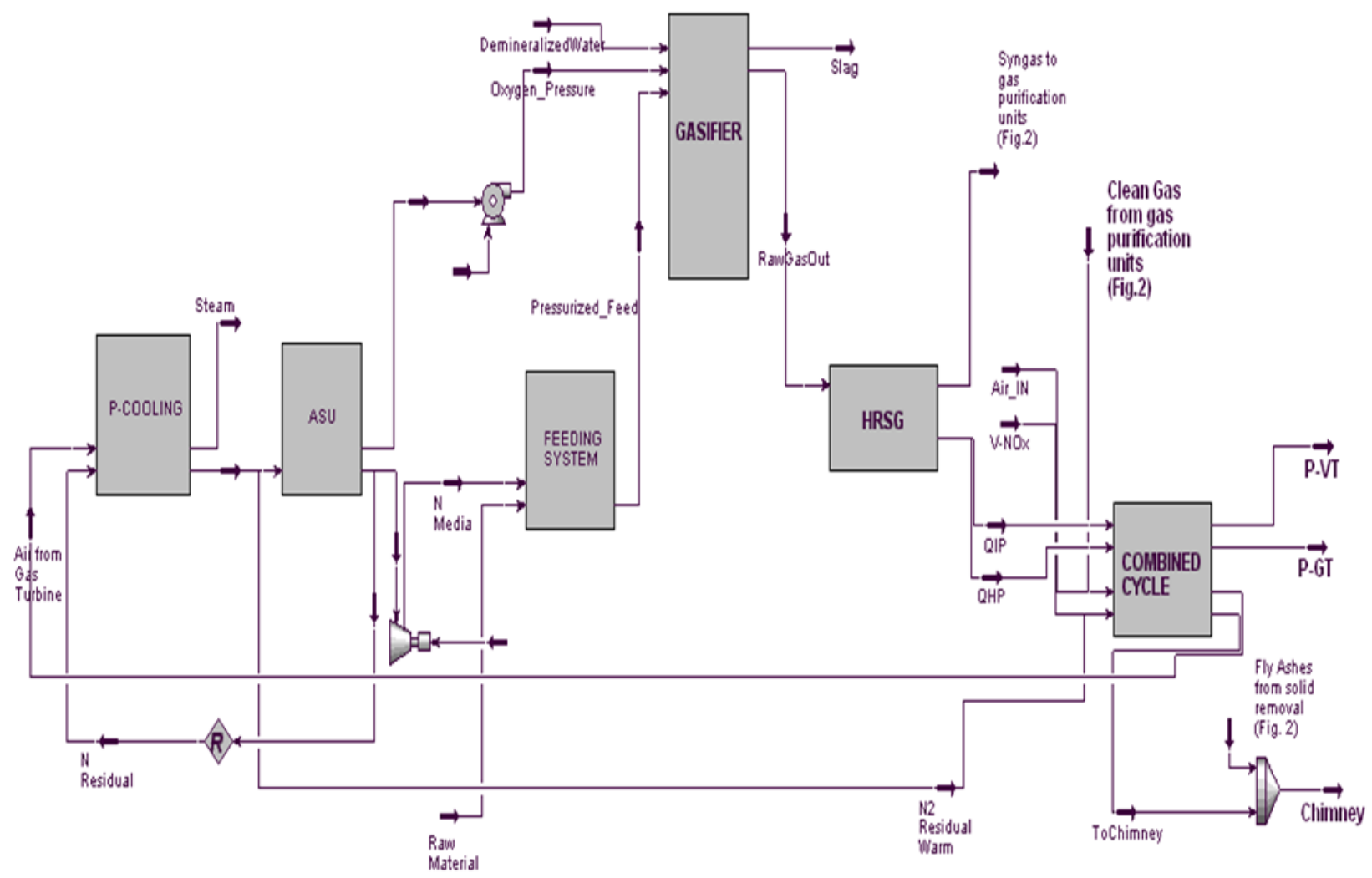

Fig. 1: Simulated Flowsheet: Pretreatment Units, Gasification and Power Generation Units (1).

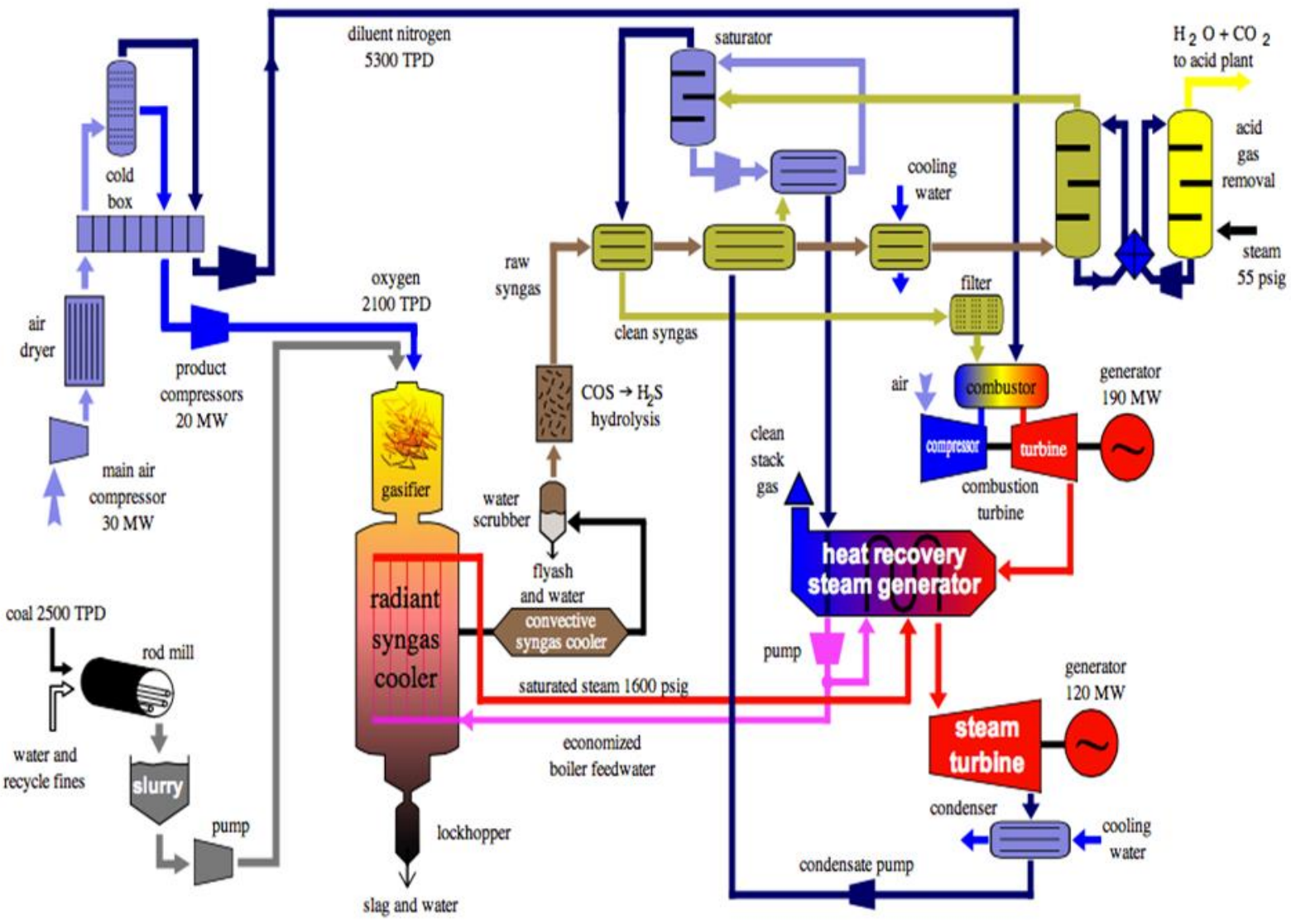

Fig. 2: Simulated Flowsheet: Pretreatment Units, Gasification and Power Generation Units. 


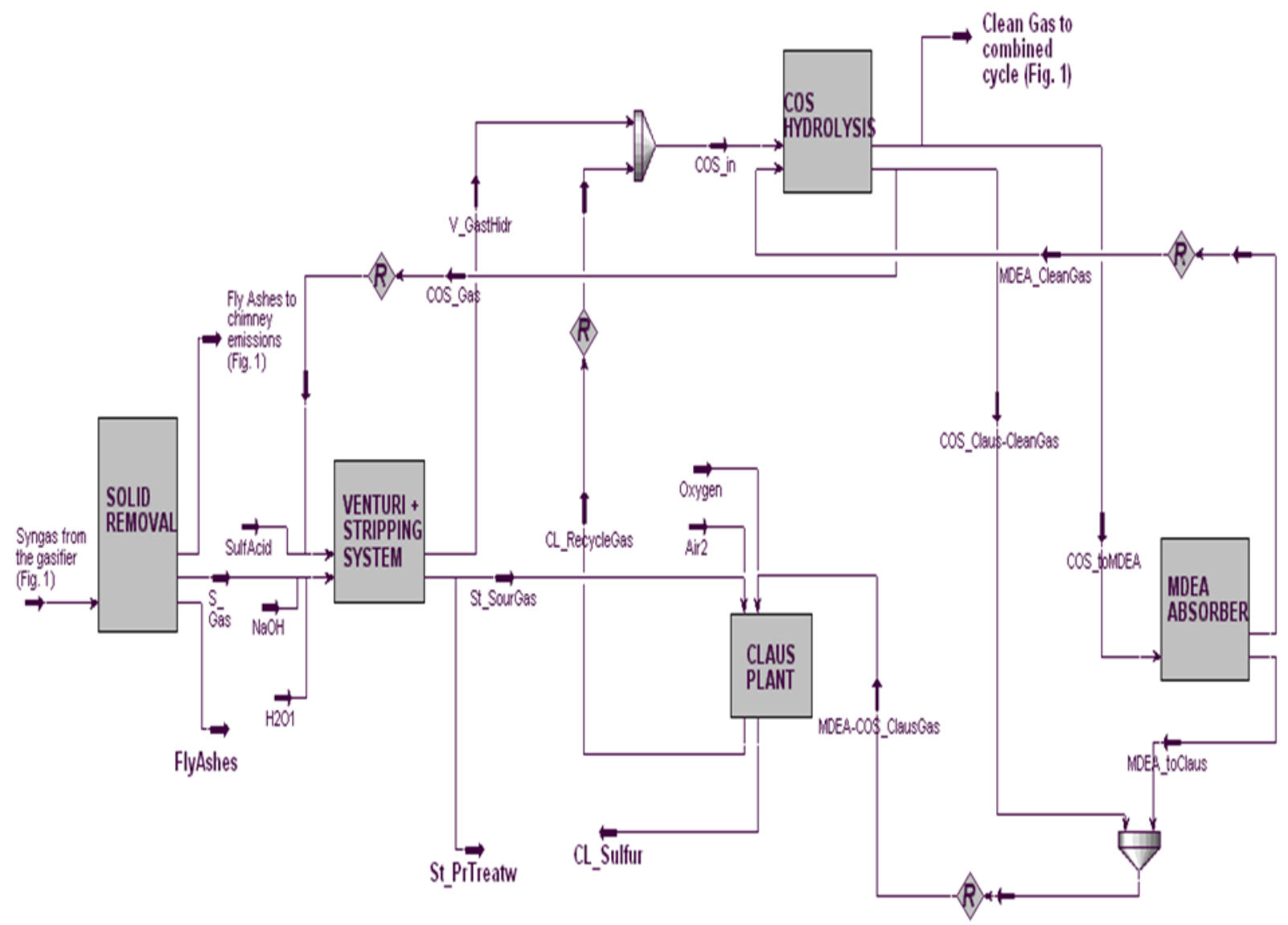

Fig. 3: Simulated Flow Sheet: Syngas Purification Units.

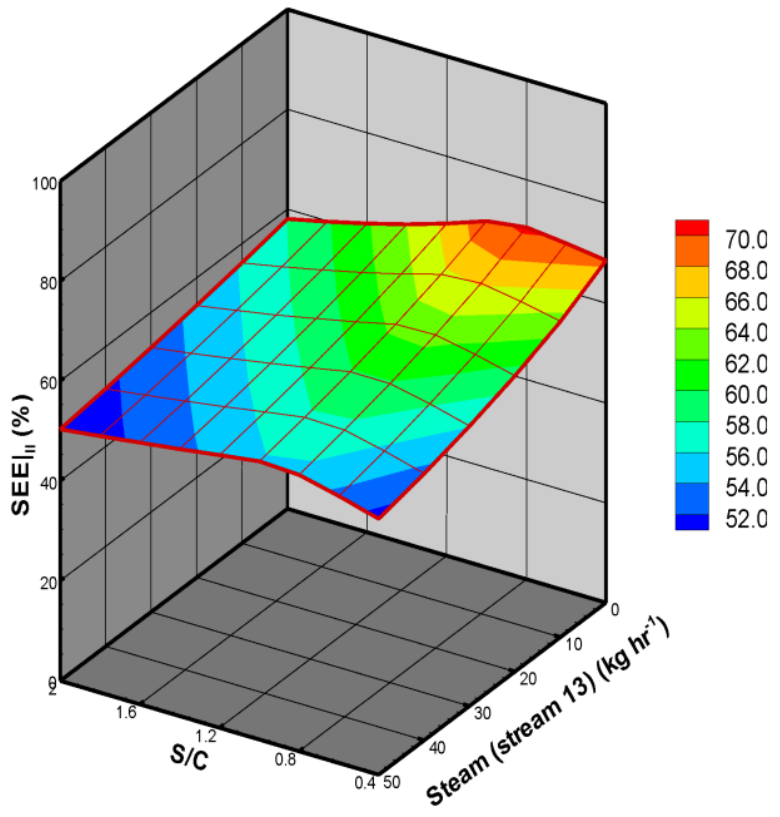

(a)

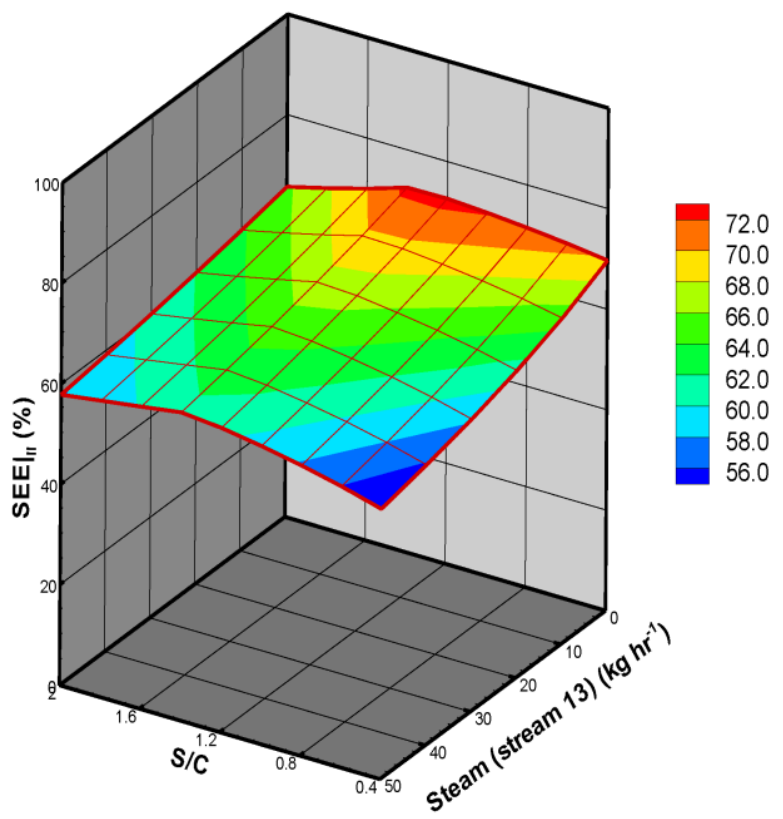

(b)

Fig .4: Three-Dimensional Distributions of the System Energetic Efficiency from the Gasification of (A) ROP; and (B) TOP. 


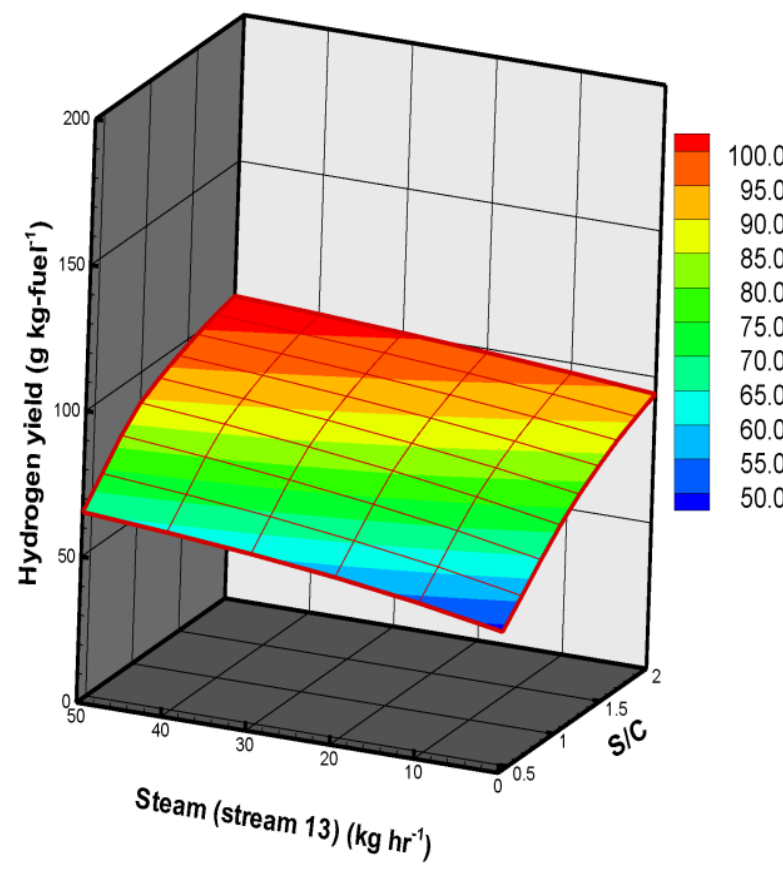

(a)

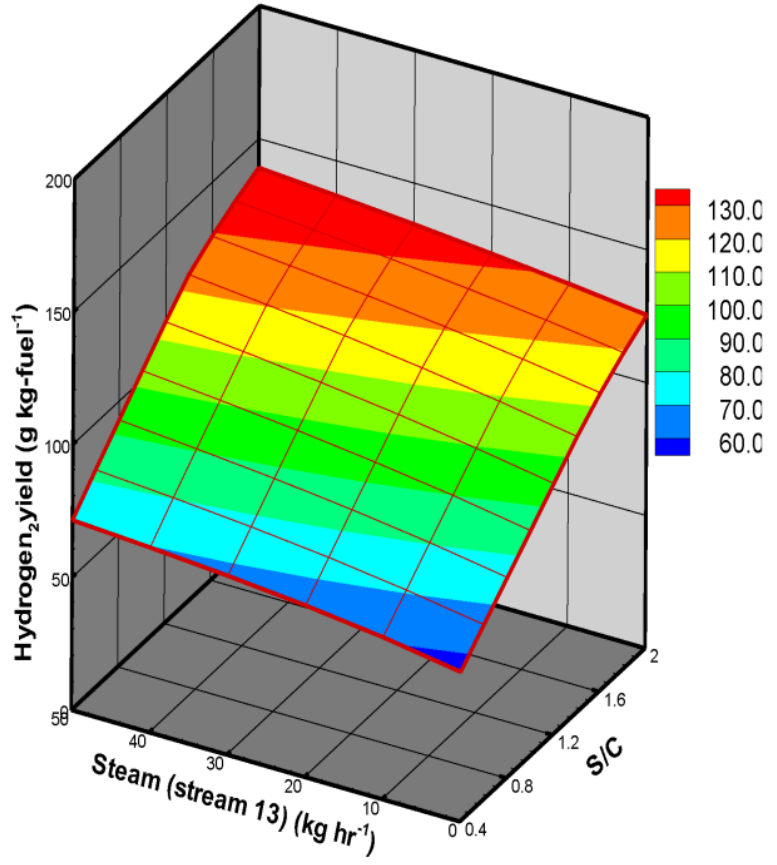

(b)

Fig .5: Three-Dimensional Distributions of Hydrogen Yield from the Gasification of (A) ROP; and (B) TOP.

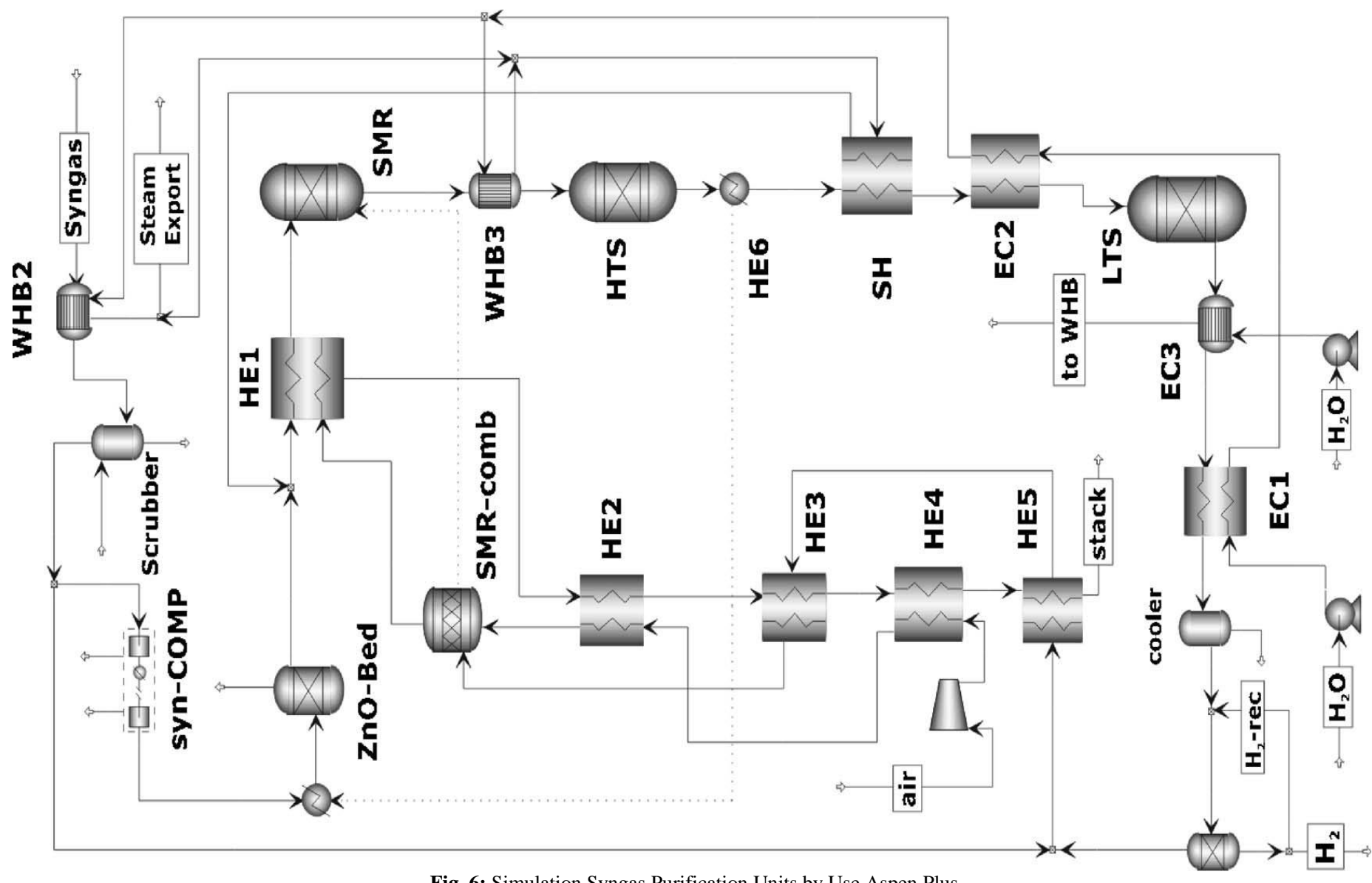

Fig .6: Simulation Syngas Purification Units by Use Aspen Plus.

\section{Plant units modeling}

In order to test the performance of the model, five sets of raw material compositions have been tested. Base case considered a mixture of 50/50\%wt of coal and pet coke. 
Input data

Table 1 presents main input parameters and conditions from the real plant that have been directly introduced in the plant simulation.

Table 1: Operating Conditions of ELCOGAS Plant (“Ar": as Received Basis."Mb": in Mass Basis).

\begin{tabular}{llllll}
\hline Input data & Base case & Mix1 & Mix 2 & Mix 3 & Mix 4 \\
\hline Coal (\%) & 50 & 39 & 45 & 54 & 58 \\
Coke (\%) & 50 & 61 & 55 & 46 & 42 \\
Carbon (\%) & 61.68 & 68.28 & 64.93 & 61.95 & 60.1 \\
Hydrogen (\%) & 2.93 & 3.21 & 3.16 & 3.07 & 3.1 \\
Nitrogen (\%) & 3.46 & 1.97 & 2.71 & 3.37 & 3.69 \\
Oxygen (\%) & 1.42 & 1.51 & 1.29 & 1.47 & 1.26 \\
Sulphur (\%) & 3.34 & 3.79 & 3.43 & 3.24 & 2.97 \\
Moisture (\%) & 2 & 0.75 & 1.04 & 1.29 & 0.93 \\
Ashes (\%) & 25.17 & 20.49 & 23.44 & 25.61 & 27.95 \\
Volatile matter (\%) & 17.3 & 16.8 & 17.1 & 18.2 & 18.5 \\
LHV (MJ/M ${ }^{3}$ ) & 37,847 & 37,197 & 37,638 & 37,997 & 38,456 \\
Feed (t/day) & 2,600 & 2,600 & 2,600 & 2,600 & 2,600 \\
Gasification temperature $\left({ }^{0} \mathrm{c}\right)$ & 1,600 & 1,600 & 1,600 & 1,600 & 1,600 \\
Gasified pressure (bar) & 25 & 25 & 25 & 25 & 25 \\
$\mathrm{O}_{2} /$ feedstock ratio (mb) & 0.715 & 0.715 & 0.715 & 0.715 & 0.715 \\
$\mathrm{H}_{2} \mathrm{O} /$ feedstock ratio (mb) & 0.13 & 0.13 & 0.13 & 0.13 & 0.13 \\
\hline
\end{tabular}

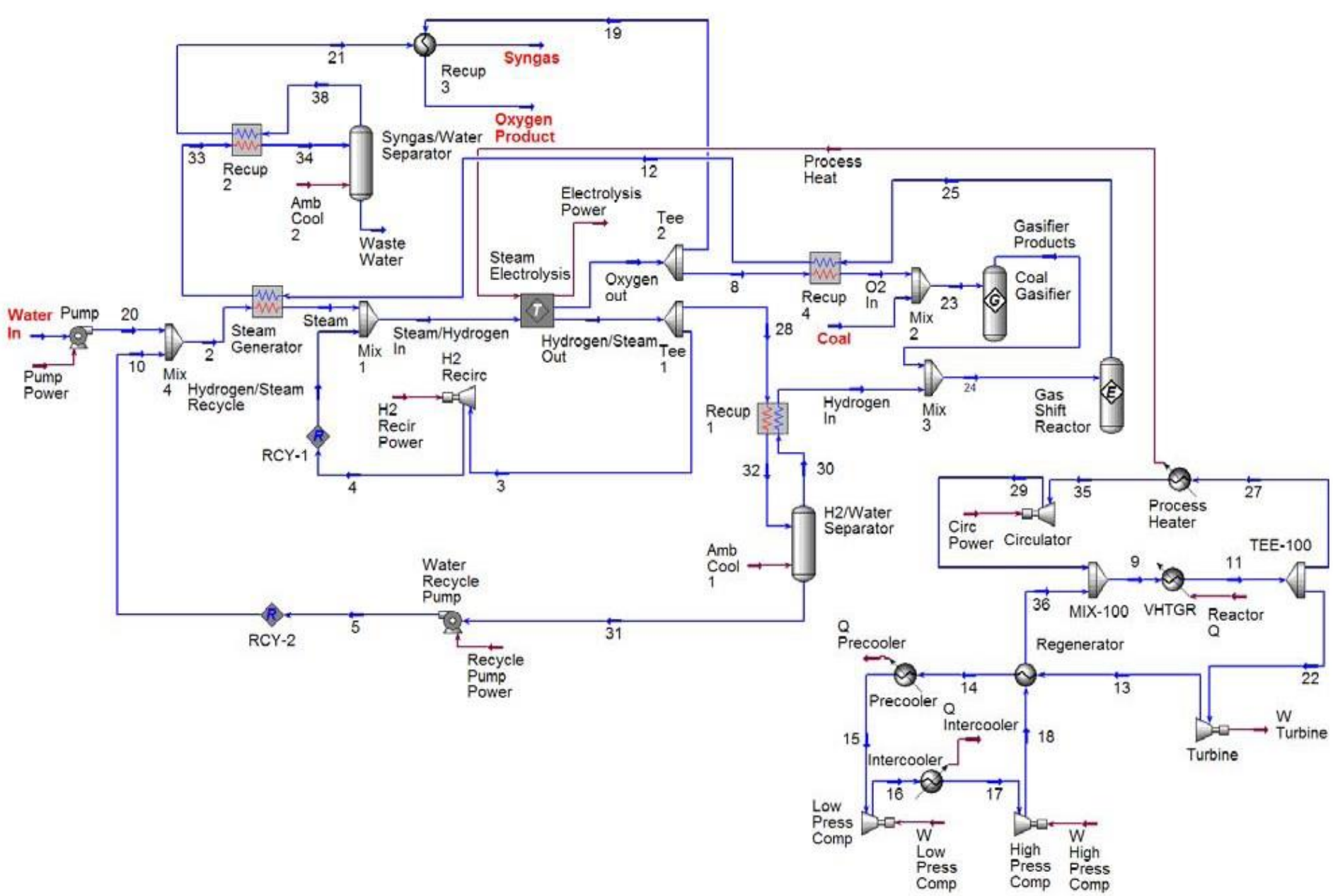

Fig .7: Advance Simulation Final of Plant

\section{Gasifier}

The conceptual model of the PRENFLO gasifier takes into account several assumptions. Firstly, it considers a nonisothermal reactor by assuming adiabatic behavior, and secondly, a feedstock that enters the reactor with a maximum of $2 \%$ wt of moisture. In a previous step to the HRSG, a quench gas cools the syngas from approximately 1600 to $800^{\circ} \mathrm{C}$. A 
conversion of around $90 \%$ of the char is obtained. The next reaction sequence is considered to take place within the gasifier model:

Pyrolysis is modeled using a series of experimental correlations from specialized literature [3], [4] which depend on temperature and volatile matter. Production of pollutant species (H2S, COS, NH3 and HCN) is represented by correlations taken from [5], [6] and industrial historical data. Every set of correlations is inferred from different coal types and analysis.

In the case of volatiles and char combustion, volatiles produced by raw material pyrolysis are considered to be consumed by complete combustion, producing $\mathrm{CO} 2$ and $\mathrm{H} 2 \mathrm{O}$. Kinetics of char combustion main reactions have been taken from [7], [8]. This step considers total oxygen consumption.

Char gasification comprises char- $\mathrm{CO}$, char- $\mathrm{H} 2 \mathrm{O}$ and char-H2 reactions. Their kinetic parameters have been taken from [7], [8].

Gas equilibrium reactions are performed by minimizing the Gibbs free energy of all present species. After this last step, syngas is obtained.

\section{Heat recovery steam generator (HRSG)}

Heat from gas turbine exhaust gases (at $535^{\circ} \mathrm{C}$ ) is mainly recovered by the HRSG which produces steam at three different pressures (127, 35 and 6.5 bar). Within the high and intermediate pressure steam circuits, extra heat recovery is achieved by cooling syngas (from 800 to $240^{\circ} \mathrm{C}$ ) and producing saturated steam.

Gas cleaning units

All purification units work at high pressure (22 bar). For the base case, this model shows good agreement between simulated results and industrial data for the outlet streams from venturi scrubber and sour water stripper (Fig. 8). In the case of the venturi, the model predicts lower compositions for all species. Stripper simulation produces values slightly higher than industrial data for $\mathrm{CO} 2$ and $\mathrm{H} 2 \mathrm{~S}$ and lower for $\mathrm{NH} 3$ and $\mathrm{HCN}$.
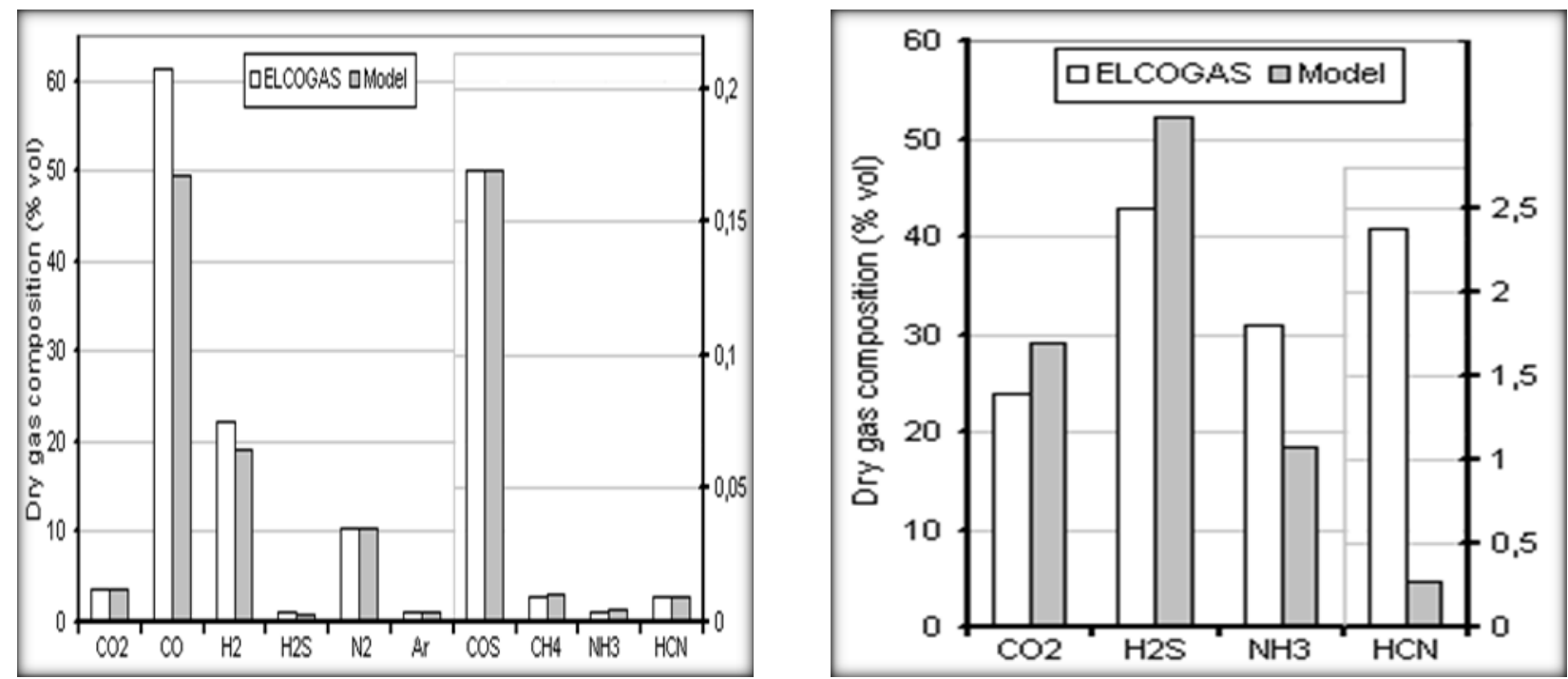

Fig. 8: Comparison of ELCOGAS Data and Predicted Values for Dry Gas Main Components of the Outlet Gas From the Venturi Scrubber (Left) and From The Sour Water Stripper (Right).

Regarding MDEA absorber behavior, (Fig. 9), a remarkable agreement exists between industrial and model predicted composition. Comparing Claus plant results (right, figure 4), main difference between predicted and industrial composition arises in CO composition. Amount of liquid sulfur removed is quite similar for both real and predicted values (3113 and $2810 \mathrm{~kg} / \mathrm{h}$, respectively). 

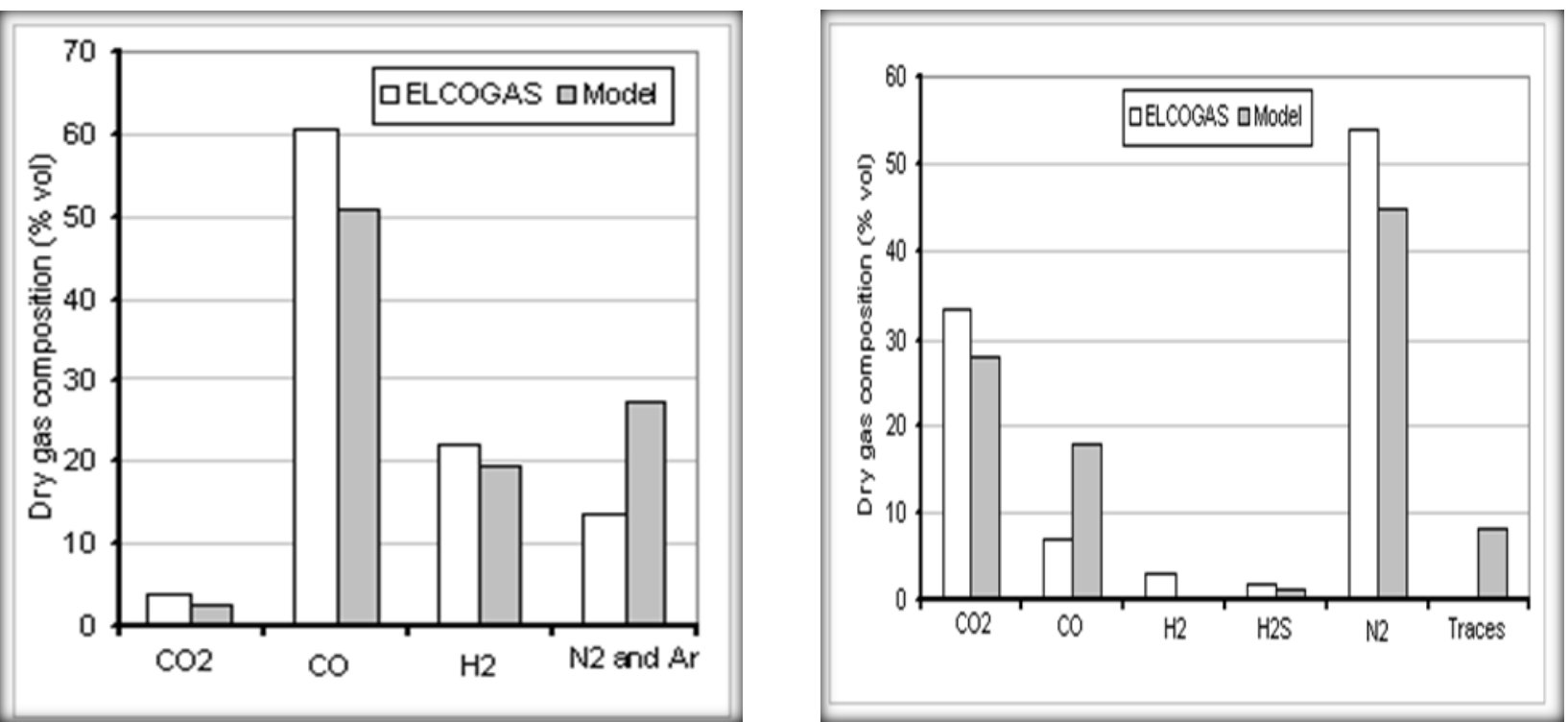

Fig. 9. Comparison of ELCOGAS Data and Predicted Values for Dry Gas Main Components of the Clean Gas (Left), and the Recycle Gas (Right)

\section{Global model results and discussion}

Table 2 shows overall simulation results compared to ELCOGAS data for different raw material mixes. Major differences are found for $\mathrm{N} 2$ and water composition in a clean gas stream. Lower volume percentages are predicted for $\mathrm{H} 2$ and $\mathrm{CO}$, while higher values are obtained for $\mathrm{H} 2 \mathrm{~S}$, COS and water simulation of produced power is in good agreement with plant data; this comparison is worst in the case of Mix4.

Table 2: Power Generation and Clean Gas Composition Comparison. Error: Total Power Deviation.

\begin{tabular}{|c|c|c|c|c|c|c|c|c|}
\hline Output data & Exp & Model & Exp. & Model & Exp. & Model & Exp. & Model \\
\hline \multicolumn{9}{|l|}{ ean gas composition } \\
\hline $\mathrm{H}_{2}($ vol. \%) & 21.11 & 19.82 & 21.17 & 19.53 & 21.14 & 19.05 & 19.8 & 18.89 \\
\hline Co (vol. \%) & 62.06 & 49.76 & 61.1 & 49.76 & 60.36 & 49.9 & 60.7 & 49.88 \\
\hline $\mathrm{Co}_{2}($ vol. \%) & 1.43 & 2.55 & 2.19 & 2.58 & 2.29 & 2.6 & 3.05 & 2.61 \\
\hline $\mathrm{N}_{2}+\operatorname{Ar}(\operatorname{vol} . \%)$ & 15.34 & 27.54 & 15.47 & 27.81 & 16.41 & 28.11 & 16.36 & 28.28 \\
\hline $\mathrm{H}_{2} \mathrm{~S}+\mathrm{COS}(\mathrm{PPM})$ & 0 & 0.36 & 0 & 0.38 & 0 & 0.39 & 0 & 0.38 \\
\hline $\mathrm{H}_{2} \mathrm{O}($ vol. \%) & 0.07 & 0.32 & 0.07 & 0.33 & 0.07 & 0.33 & 0.08 & 0.33 \\
\hline $\mathrm{LHV}\left(\mathrm{MJ} / \mathrm{M}^{3}\right)$ & 8.259 & 7.985 & 8.126 & 7.956 & 8.038 & 7.923 & 7.796 & 7.905 \\
\hline $\begin{array}{l}\text { Gas turbine } \\
\text { power(mw) }\end{array}$ & 168.7 & 187.5 & 173 & 183.9 & 163 & 181.4 & 137.8 & 180.6 \\
\hline $\begin{array}{l}\text { Steam turbine } \\
\text { power(mw) }\end{array}$ & 121.5 & 112.5 & 130 & 109 & 124.8 & 108 & 109.7 & 105.8 \\
\hline Total power (mw) & 290.2 & 299.7 & 303 & 293 & 287.8 & 289.4 & 247.5 & 286.4 \\
\hline Error $(\%)$ & & 3.27 & & -3.30 & & 0.56 & & 15.72 \\
\hline
\end{tabular}

Differences may be caused by a combined effect of several simplifications that this models relies on. Pyrolysis model estimates char, nitrogen and sulphur compounds production. And it is based on experimental correlations. Char combustion and gasification reactions are also based on experimental correlations. However, these correlations have been taken from the literature and do not exactly correspond to the actual raw material mixtures. ANN results are limited to an interval of variation of gases composition. Also, the combustion of the clean gas is modeled with a Gibbs reactor.

A validated conceptual model of an IGCC power plant of co-gasification has been performed with a very good agreement between model results and ELCOGAS data. Future work will be envisaged to further improve the model simplifications and optimize the process based on economic and environmental considerations. The study presented a conceptual design of the BSG process using an Aspen Plus simulator. The results show that the optimum conditions of ROP and TOP are at the S/C ratios of 1.0 and 1.4, respectively. Under these conditions, a maximum SEE of $73.38 \%$ and a hydrogen yield of $72.74 \mathrm{~g} / \mathrm{kg}$-fuel are achieved from ROP steam gasification. The SEE and hydrogen yield values can be enhanced when ROP undergoes Torre faction at $250{ }^{\circ} \mathrm{C}$. Accordingly, TOP is recommended to produce hydrogen 
enriched gas. To enhance the SEE from TOP, a heat recovery step is added to the BSG process. With regard to the heat recovery design, the SEE of TOP is amplified by a factor of $2.49 \%-44.61 \%$ when the S/C ratio is below 1.2 . Therefore, this design can be used to enhance the system energetic efficiency from the steam gasification process of torrefied oil palm. Finally, the optimum S/C ratio is 1.36 , based on the optimal strategy for maximizing the SEE.

\section{References}

[1] IGCC Puertollano ELCOGAS, 2001, A clean coal gasification power plant.

[2] CSIC (Consejo Superior de Investigaciones Científicas), Jaume Almera Institute, Spain.

[3] S.Balzioc and P.G.W. Hawksley, Ind. Eng. Chem. Process Des. Dev. (1970), 9, no. 4, p 521.

[4] R. Loison and R. Chauvin, Chimie et Industrie, (1964), 91, no. 3, p 269.

[5] F. García-Labiano, J. Adánez et al., Fuel, (1996), 75, no. 5, p 585 http://dx.doi.org/10.1016/0016-2361(95)00291-X

[6] S. Kambara, T. Takarada et al., Energy \& Fuels (1993), 7, 1013 http://dx.doi.org/10.1021/ef00042a045.

[7] Wen, C. Y. and Chaung, T. Z. Ind. Eng. Chem. Process Des. Dev, (1979), 18, no.4, p 684 http://dx.doi.org/10.1021/i260072a020

[8] Govind, R. and Shah, J., AIChE Journal, (1984), 30, 79. http://dx.doi.org/10.1002/aic.690300113. 